\title{
Caso dunas de Concón: Acerca de la obligatoriedad de someterse al Sistema de Evaluación de Impacto Ambiental (Corte Suprema)
}

\author{
Comentario de Iván Hunter Ampuero
}

Santiago, veintisiete de julio de dos mil doce.

\section{VISTOS:}

Se reproduce la sentencia en alzada con excepción de sus fundamentos sexto a undécimo que se eliminan.

\section{Y SE TIENE EN SU LUGAR Y ADEMÁS PRESENTE:}

Primero: Que el acto que motiva la interposición de la presente acción constitucional por parte de don René González Torres, Diputado por Viña del Mar y Concón; Francisco Chahuán Chahuán, Senador de la República; Jorge Valdovinos Gómez, Alcalde de la I. Municipalidad de Concón y doña María José Aguirre Neuenschwander, Presidenta de la Organización Comunitaria Red Duna, es la decisión de la recurrida Sociedad Urbanizadora Reñaca Concón S.A. de disponer el cierre del perímetro para acceder al campo dunar denominado "Dunas de Concón", predio perteneciente a la recurrida que tiene una extensión de 45 hectáreas y dentro del que se emplaza -conforme a lo dispuesto por el Decreto Supremo No 481 de 1993- un santuario de la naturaleza, que es el hábitat de decenas de especies animales y vegetales.

Expresan los recurrentes que los hechos llevados adelante por la sociedad Reconsa S.A. y que se manifiestan concretamente en cercar el campo dunar, implican una vulneración al derecho a vivir en un medio ambiente libre de contaminación, garantía consagrada en el artículo $19 \mathrm{~N}^{\circ} 8$ de la Constitución Política de la República, infringiendo asimismo lo dispuesto en el artículo 10 letra p) de la Ley $\mathrm{N}^{\circ} 19.300$ que exige someter a sistema de evaluación de impacto ambiental la ejecución de obras en santuarios de la naturaleza.

SEGUNDO: Que la sociedad recurrida al evacuar el informe requerido expresa ser la dueña de los terrenos dentro de los que se emplaza el campo dunar y, que, la decisión de cerrar el acceso al santuario se debe al deterioro sufrido en el lugar producto del ingreso de vehículos motorizados y personas que destruían la flora y fauna del lugar. Expone que fue la propia autoridad edilicia quien los conminó a tomar medidas de 
conservación de su terreno, lo que finalmente culmina con el cierre, que tiene por fin evitar mayores detrimentos en las "Dunas de Concón".

Tercero: Que la Ley N 19.300 sobre Bases Generales del Medio Ambiente en su artículo 10 letra p) dispone: "Los proyectos o actividades susceptibles de causar impacto ambiental, en cualquiera de sus fases, que deberán someterse al sistema de evaluación de impacto ambiental, son los siguientes: p) Ejecución de obras, programas o actividades en parques nacionales, reservas nacionales, monumentos naturales, reservas de zonas vírgenes, santuarios de la naturaleza, parques marinos, reservas marinas o en cualesquiera otras áreas colocadas bajo protección oficial, en los casos en que la legislación respectiva lo permita”.

No debe olvidarse que la Ley $\mathrm{N}^{\circ} 19.300$ constituyó una ley marco en materia ambiental que se hizo aplicable a todas las actividades o recursos respecto de los cuales posteriormente se crearon leyes especiales y que se sustenta en principios que permiten dar coherencia a la ley y sin los cuales se consideró que no se podía entender plenamente su real alcance y pretensiones ellos son: el principio preventivo; el principio que quien contamina paga; el gradualismo; el principio de la responsabilidad; el principio participativo; y el principio de la eficiencia.

Cunto: Que en lo que interesa a esta decisión, resulta trascendente detenerse en el principio preventivo. De acuerdo al Mensaje Presidencial, con el que se inicia el proyecto de la Ley $\mathrm{N}^{\circ} 19.300$, se dijo que: "mediante este principio, se pretende evitar que se produzcan los problemas ambientales. No es posible continuar con la gestión ambiental que ha primado en nuestro país, en la cual se intentaban superar los problemas ambientales una vez producidos. Para ello, el proyecto de ley contempla una serie de instrumentos". Dentro de estos instrumentos se citó el sistema de impacto ambiental y se dijo: "El proyecto de ley crea un sistema de evaluación de impacto ambiental. En virtud de él, todo proyecto que tenga un impacto ambiental deberá someterse a este sistema. Este se concreta en dos tipos de documentos: la declaración de impacto ambiental, respecto de aquellos proyectos cuyo impacto ambiental no es de gran relevancia; y los estudios de impacto ambiental, respecto de los proyectos con impactos ambientales de mayor magnitud. En virtud de estos últimos, se diseñarán, previamente a la realización del proyecto, todas las medidas tendientes a minimizar el impacto ambiental, o a medirlo, o incluso, a rechazarlo".

El principio preventivo, a diferencia del precautorio que actúa bajo supuestos ya comprobados, solamente requiere de un riesgo racional y evidente previamente demostrado, que sea verosímil de producirse sobre la base de estudios especializados que lo demuestren, es el fumus bonis iuris, para luego determinar la gravedad del mismo acontecimiento, que exista la posibilidad de sufrir un perjuicio importante, la alteración o el agravamiento de una determinada situación que, en el evento que ocurra, afectaría un interés legítimo (periculum in mora). Resulta pertinente acotar que no se busca que la actividad de los particulares quede en estándares de riesgo cero, sino que, como primera medida, los riesgos advertidos por estudios fundados sean considerados y se adopten 
respecto de ellos las medidas pertinentes, que no se les ignore. Posteriormente se deben evaluar riesgos y mitigaciones para llegar a una decisión racional, conforme a la cual los peligros o inseguridades son minimizados por medidas efectivas y, en el evento que estos se produzcan se han considerado las acciones de reacción inmediatas, que ante una omisión en su planificación deben ellas ser improvisadas, con el consiguiente agravamiento del daño. Es por lo anterior que el principio preventivo actúa sobre una hipótesis racional y estudios especializados, circunstancias que en el caso de autos concurren.

Quinto: Que de los elementos de juicio que obran en estos antecedentes se advierte que Reconsa S.A. ha omitido ingresar el proyecto que pretende desarrollar en su terreno -donde se emplaza un santuario de la naturaleza y señalando que el cierre es una obra menor sin que conste en parte alguna la magnitud o envergadura real de ella- ante la autoridad competente, con la finalidad de que se elabore un Proyecto de Impacto Ambiental, requisito indispensable para asegurar el respeto a la normativa medioambiental, y dejar claramente establecido que con la ejecución de faenas en el terreno dentro del que se sitúa el santuario, no va a existir algún tipo de riesgo o alteración en el valor paisajístico o turístico de la zona en que han de emplazarse las obras que pretenden ser llevadas a cabo por parte del dueño del terreno. Más aún, tomando en consideración que al preguntar la recurrida sobre la factibilidad de someter el cierre del inmueble al SEIA, se le señala que la respuesta que se le entrega se elabora en base a los antecedentes por Reconsa S.A. presentados, los que son de su exclusiva responsabilidad (punto 7 . del documento que rola a fojas 130) de manera que no hay control alguno que permita asegurar el cumplimiento de las normas contenidas en la Ley $\mathrm{N}^{\mathrm{o}} 19.300$.

Sexto: Que por lo reseñado es posible advertir que en el caso de autos se verifica un obrar ilegal por parte del dueño de los terrenos que por medio de cierres pretende ejercer su dominio, sin someter la ejecución de las obras que busca efectuar en el campo dunar a una Evaluación de Impacto Ambiental, que garantice que estas cumplen con la normativa vigente e importa la vulneración de la garantía consagrada en la Carta Fundamental que confiere el derecho a vivir en un medio ambiente libre de contaminación.

SÉPtimo: Que sin perjuicio de lo expuesto precedentemente cabe consignar que en la actualidad se encuentran paralizados los permisos de edificación de la zona del campo dunar, por el inicio del estudio para efectuar un cambio al plan regulador comunal, decisión que se materializó en la dictación del Decreto Alcaldicio $\mathrm{N}^{\circ} 3$ de 3 de enero del año en curso.

Dicho Decreto Alcaldicio fue objeto de un recurso de protección interpuesto por la sociedad Reconsa S.A., que tenía por objeto dejar sin efecto la paralización decretada por la autoridad municipal, acción rechazada por la Corte de Apelaciones de Valparaíso por sentencia de 16 de marzo de 2012, decisión que fue confirmada por esta Corte con fecha 8 de mayo pasado. 
Octavo: Que de este modo y encontrándose postergados los permisos de edificación no es factible materializar obra alguna por parte de la recurrida en el sector del "Campo Dunar de Concón” de manera que el presente recurso debe ser acogido.

De conformidad asimismo con el artículo 20 de la Constitución Política de la República y el Auto Acordado de esta Corte sobre la materia, se revoca la sentencia apelada de 14 de febrero de dos mil doce, escrita a fojas 84 y en su lugar se declara que se acoge el recurso de protección interpuesto en lo principal de fojas 1 disponiéndose que no pueden efectuarse obras de ningún tipo en el Campo Dunar de Concón.

Acordado lo anterior con el voto en contra de los abogados integrantes señor Pfeffer y señor Prieto quienes fueron del parecer de confirmar la sentencia en alzada en virtud de los fundamentos expresados en ella en el voto de mayoría y agregando los siguientes fundamentos:

$1^{\circ}$ ) Que según establece el artículo 844 del Código Civil, "El dueño de un predio tiene derecho para cerrarlo o cercarlo por todas partes, sin perjuicio de las servidumbres constituidas a favor de otros predios. El cerramiento podrá consistir en paredes, fosos, cercas vivas o muertas". Este derecho del dueño constituye también una obligación para éste cuando se trata de un sitio eriazo, que no se encuentra cercado frente al espacio público y está ubicado en el área urbana, según se desprende del artículo 2.5.1 de la Ordenanza General de Urbanismo y Construcción que señala: "Los sitios eriazos y las propiedades abandonadas con y sin edificación, ubicadas en áreas urbanas, deberán tener cierros levantados en su frente hacia el espacio público, siendo responsabilidad de los propietarios mantenerlos en buen estado".

$2^{\circ}$ ) Que con el objeto de ejercer el propietario su derecho a cerrar o cercar su predio y a la vez cumplir con la obligación de tener cierros, de acuerdo a las normas antes citadas, no requiere de solicitar un permiso de obra menor o especial ante la Dirección de Obras Municipales, puesto que un cerco no constituye una "obra menor" según está definido por el artículo 1.1.2 de la Ordenanza General de Urbanismo y Construcción, siempre y cuando dicho cerco o cierro cumpla con las exigencias, especificaciones y normativa que establece el Plan Regulador Comunal respectivo para el sector donde se ubica el inmueble.

$3^{\circ}$ ) Que la postergación de los permisos de subdivisión, loteo o urbanización predial y de construcción establecidos por Decreto Alcaldicio $\mathrm{N}^{\circ} 3$ de enero de 2012 de la Ilustre Municipalidad de Concón, y que fuera objeto de un recurso de protección interpuesto por la sociedad Reconsa S.A., acción rechazada por la Corte de Apelaciones de Valparaíso por Sentencia de 16 de marzo de 2012, y confirmada por esta Corte con fecha 8 de mayo del año en curso, no influye ni afecta al derecho y obligación del dueño del predio a cercar, por cuanto no requiere de permiso municipal para este cometido como ya se indicó precedentemente.

$4^{\circ}$ ) Que, asimismo, el cercar el Santuario de la Naturaleza en aquella parte marcada con línea roja en el documento número 3 acompañado en el primer otrosí del escrito que corre a fojas 15 y que corresponde sólo a la parte que limita con el Camino Reñaca a Concón, no requiere de autorización del Servicio de Evaluación Ambiental para su ejecución, según se indica en informe del Servicio de Evaluación Ambiental de Valparaíso 
de fecha 17 de febrero de 2012, agregado a fojas 130 de autos, que respondiendo a una consulta de la recurrida señala en sus puntos cinco y seis: "5. Que, según lo informado por usted, la iniciativa que se contempla ejecutar consiste en el cierre perimetral de los terrenos que colindan con el Santuario de la Naturaleza "Campo Dunar" de Concón, solo en la parte que limita con el Camino Reñaca-Concón. Así, el cierre perimetral en este caso es considerado una obra de menor envergadura, más aún si este implica el borde solo de una parte del Santuario y no la totalidad del mismo. 6. Por lo tanto, en atención a lo expuesto precedentemente, considerando lo instruido mediante Ord. N N $^{\circ} 103050$ del 23 de septiembre de 2010 de la Comisión Nacional del Medio Ambiente "Instructivo sobre consultas de pertinencia de ingreso de proyectos o actividades al SEIA", lo instruido en el Ord. N 020799 de fecha 13 de febrero de 2002, sobre "Áreas Protegidas en el Sistema de Evaluación de Impacto Ambiental” y los antecedentes por Ud. entregados, el cierre de predio que contiene al Santuario de la Naturaleza Campo Dunar de Concón no debería ingresar al Sistema de Evaluación de Impacto Ambiental, sin perjuicio del cumplimiento de la normativa ambiental vigente".

$5^{\circ}$ ) Que sin perjuicio de lo anterior, debe considerarse además que la acción de cercamiento -facultad que emana del dominio- se justifica plenamente en el presente caso, precisamente para tutelar el medio ambiente frente al hecho público y notorio de que terceros ingresan al área de protección para desarrollar actividades que objetivamente dañan la naturaleza, por lo que en caso alguno una medida adoptada por el dueño con la finalidad de controlar el ingreso podría calificarse de arbitraria o ilegal, tanto más si la misma había sido insinuada por el Alcalde de la I. Municipalidad de Concón;

$\left.6^{\circ}\right)$ Que, por consiguiente, al no concurrir ninguno de los presupuestos que exige el artículo 20 de la Carta Fundamental para acoger la presente acción constitucional la misma ha debido rechazarse.

Regístrese y devuélvase con sus agregados.

Redacción a cargo del Ministro señor Muñoz y la disidencia de los señores Pffefer y Prieto.

Rol No 2138-2012.

\section{Comentario}

La presente sentencia de la Corte Suprema acoge un recurso de protección interpuesto por un grupo de políticos de Viña del Mar y Concón, y una organización comunitaria de esa misma comuna, en contra de la Sociedad Urbanizadora Reñaca Concón S.A. La recurrida había dispuesto el cierre del perímetro para acceder al campo dunar denominado "Dunas de Concón", emplazadas en un terreno de su dominio y que constituye un santuario de la naturaleza de conformidad al Decreto Supremo No 481 de 1993. La Corte Suprema estima que esta obra, atendido lo dispuesto en la letra p) del Art. 10 de la ley 19.300 (en adelante, LGBMA), tiene que someterse al Sistema de Evaluación de Impacto Ambiental (en adelante, SEIA). Al respecto se fundamenta - grosso modo- que 
la única forma de asegurar el respeto de la normativa ambiental, como también de que no va a existir riesgo o alteración en el valor paisajístico o turístico en la zona en que se van a emplazar las obras, es elaborando un "Proyecto de Impacto Ambiental". De esta forma, la omisión de someter el proyecto en cuestión al SEIA, transforma esa obra en un acto ilegal que vulnera el derecho constitucional de vivir en un medio ambiente libre de contaminación.

El sistema chileno de evaluación de impacto ambiental funciona en base a un catálogo cerrado de proyectos y actividades a los que el legislador "presume de derecho" que son susceptibles, en cualquiera de sus etapas (construcción, operación o abandono), de provocar impactos ambientales (Art. 10 LGBMA). En línea de principio podría afirmarse que estas actividades y proyectos deben someterse previa y obligatoriamente a este sistema, con total prescindencia de sus características y objetivos ${ }^{1}$. Tal conclusión es correcta, pero llevarla a sus extremos podría generar serios problemas para la gestión de aquellos lugares indicados en la letra p) del Art. $10^{2}$. Y eso es precisamente lo criticable del fallo de la Corte.

¿Era posible que la Corte argumentara en otro sentido a pesar del tenor literal de esta norma? Mi impresión es que sí, y para ello quiero efectuar un doble ejercicio: uno teórico acerca de la función de los jueces en un Estado Democrático de Derecho, y otro, más del tipo sistemático, destinado a ver la coherencia de la decisión de la Corte Suprema en el contexto del SEIA.

Hace un par de años en un espectacular artículo Fernando Atria ${ }^{3}$ enseñaba que la principal función de la jurisdicción era tratar los casos en sus propios términos, ajustando la impropiedad de los textos legales cuando estos no representaban el pensamiento del legislador. Esto significa que si existen buenas razones para apartarse de las que justifican la aplicación de una norma jurídica entonces es deber de los jueces no aplicarla. Y creo que este es uno de los casos, en la medida que existen razones poderosas para entender que no estamos en presencia de una situación que amerite la utilización del SEIA. Este sistema de carácter preventivo busca alcanzar un objetivo de política general: un desarrollo ambientalmente sustentable ${ }^{4}$. Este concepto exige equilibrar dos intereses en conflicto: por un lado, el del titular de un proyecto o actividad que busca una ganancia a costa de sacrificar "parte" del medio ambiente, y del Estado, que tiene el deber de proteger y promover el medio ambiente y el patrimonio ambiental. Este sentido no tiene cabida

${ }^{1}$ Obviamente que esta afirmación requiere ser morigerada desde que el Reglamento del SEIA (en adelante, el Reglamento) consolida una serie de parámetros para definir cuándo los proyectos y actividades señaladas en el Art. 10 deben someterse al sistema. No obstante, respecto de la letra p) de esa disposición el Reglamento no indica absolutamente nada.

${ }^{2}$ Por ejemplo, la construcción de una cabaña para un guarda parques emplazada en un parque nacional requeriría someterse al SEIA al tratarse de un obra; la construcción de un pequeño mirador emplazado en un santuario de la naturaleza también requeriría someterse al SEIA.

${ }^{3}$ Me refiero al artículo: "Jurisdicción e independencia judicial. El poder judicial como poder nulo", en Revista de Estudios de la Justicia, N 5, 2004, pp. 119 a 141.

${ }^{4}$ Ormazábal, C., "Sistema de Evaluación de Impacto Ambiental (I). Análisis crítico del marco legal y su reglamento”, en Ambiente y Desarrollo, Vol. XIII, No 3, 1997, p. 47. 
en el presente caso, ya que no se trata de imbricar intereses contrapuestos. Al contrario, un particular que con el afán de proteger el santuario de la naturaleza frente a los actos que habitualmente lo colocan en riesgo ejecuta una obra menor -cierre perimetral-sin obtener un beneficio directo o indirecto. La acción del particular no era para obtener un beneficio sino para colaborar con el Estado en la gestión del patrimonio ambiental, cuestión que al menos en nuestro país y luego de esta sentencia, parece estar destinada al fracaso ${ }^{5}$.

En una interpretación sistemática el Reglamento establece una serie de parámetros cuantitativos para definir si un proyecto o actividad debe someterse al Sistema. De esto queda sumamente claro que no toda actividad o proyecto requiere una evaluación de sus impactos ambientales -rompiendo con el esquema inicial propuesto por el Art. 10 LGBMA- sino solo aquellos que por su envergadura o naturaleza pueden generar impactos. Uno de los grandes problemas que presenta el Reglamento es que existen varias situaciones en las no que se efectúa un trabajo de precisión cuantitativo del proyecto o actividad, frente a otros donde sí existen parámetros objetivos que determinan cuándo debe ingresar al SEIA ${ }^{6}$. Uno de los casos en que no existe esa precisión es respecto de los proyectos o actividades a ejecutarse en los santuarios de la naturaleza. Esto supondría, en una primera lectura, que todas las obras a ejecutarse en un santuario de la naturaleza requieren evaluación ambiental.

No obstante, una interpretación sistemática y coherente, y por sobre todo racionalmente practicable, exige que se trate de una obra de cierta envergadura que vaya a ejecutarse en uno de esos lugares, o más precisamente, una obra de tamaño similar a las que indica el Reglamento en otros literales. Un cierre perimetral, por definición, no puede catalogarse como obra de envergadura, y exigir prueba de que no afecta el medio ambiente, el paisaje o el turismo, no parece ajustarse a su propia naturaleza, y constituye una exigencia al menos excesiva.

Por otra parte, es cierto que toda actividad humana supone la creación de un riesgo ${ }^{7}$, pero la construcción de un cierro en los términos planteados en el caso tiene un riesgo mínimo, perfectamente identificable, que no escapa del conocimiento humano, previsible, y además, fácilmente controlable. Someter un proyecto o actividad al SEIA se justifica en la medida que sea necesario identificar y evaluar los riesgos ambientales, y eventualmente, prevenir, compensar y mitigar los impactos que se puedan generar ${ }^{8}$.

${ }^{5}$ Entiendo que la finalidad con que actuó el privado, amén de señalarse en el recurso, no podría ser otra que otorgar protección al santuario. En ninguna parte del recurso ni del fallo se indica que el cierre de las Dunas tenían un carácter previo y relacionado a otro proyecto o actividad empresarial. Ciertamente lo pudo ser, pero no es un hecho que ha sido establecido en la sentencia.

${ }^{6}$ Para una explicación más detallada de esta crítica: Ormazábal, C., "Sistema de Evaluación de Impacto Ambiental (I). Análisis crítico del marco legal y su reglamento”, cit., p. 48.

${ }^{7}$ Evans, Jhon, et al., Introducción al análisis de riesgos ambientales, Secretaria de Medio Ambiente y Recursos Naturales, Instituto Nacional de Ecología, México, 2003, p. 11.

${ }^{8}$ Vid., Martin Mateo, R., Tratado de Derecho Ambiental, Vol. I, Editorial Trivium, Madrid, 1999, p. 303. 
Solo una obra que no consista precisamente en un cierro perimetral puede generar esos impactos, cuestión que al menos en este caso no se cuestionó.

Por eso creo que la Corte Suprema resolvió incorrectamente al aplicar en forma literal una disposición cuando existían poderosas razones para entender que se trata de una norma impropia, que debió ser ajustada a los términos del caso concreto. Resulta evidente que la universalización del contenido de esa decisión llega a resultados seguramente no deseados ni queridos por el legislador, y por sobre todo, dificulta la gestión de aquellos lugares indicados en la referida disposición. Esto es lo que justifica que el ejercicio de aplicar las normas lo hagan los jueces. 